\title{
ENTRE POSITIVISMO E PÓS-POSITIVISMO: FLEXIBILIZAÇÃO DE ELEMENTOS NOS ESCRITOS DE NORBERTO BOBBIO
}

\section{Luciene Dal Ri ${ }^{1}$}

\section{Resumo}

A contribuição de Norberto Bobbio para a teoria geral do direito é composta por várias fases que vão desde a pesquisa em temas voltados ao costume e à analogia, ao interesse crítico pelo positivismo normativo e por fim ao caráter funcional do direito. Os interesses de pesquisa do autor italiano enriquecem sua trajetória e delineiam a flexibilização de elementos do positivismo normativo, permitindo o alargamento do campo do direito à sociologia, à política e à filosofia do direito. Neste artigo, questiona-se se a flexibilização de alguns elementos da doutrina positivista permite compreender a concepção do direito de Bobbio como pós-positivista. Nesse contexto, consideram-se os escritos de Bobbio e confrontam-se as opiniões de Luigi Ferrajoli que o define como paleo-positivista, e de Mario Losano que analisando a pluralidade de fases de pesquisa de Bobbio, considera sua última fase, a partir da década de 70, como pós-positivista. Como resultado obteve-se que Bobbio pode ser entendido, sob certos aspectos, como pós-positivista, considerando a flexibilização de elementos do positivismo normativo e a dinâmica de ampliação dos critérios de aplicação do direito, abarcando uma concepção funcional e permeável pelos ideais de liberdade e justiça.

Palavras-chave: Norberto Bobbio; Positivismo Jurídico; Pós-Positivismo; Sociologia; Função do Direito.

\section{INTRODUÇÃO}

A obra de Norberto Bobbio tem uma considerável contribuição ao estudo da filosofia e da teoria geral do direito, bem como da política do século XX. Em âmbito jurídico, a influência de Bobbio explica-se principalmente por meio do estudo do positivismo normativo, manifesto em artigos e livros.

A trajetória de pesquisa de Bobbio é muito ampla, sendo marcada por reflexões analíticas influenciadas por autores como Santi Romano, Tullio Ascarelli e Hans Kelsen, além de poder ser dividida em diferentes fases. ${ }^{2}$ A primeira fase é dedicada à problemas específicos de filosofia e de teoria geral do direito, abordando temas estranhos ou contrapostos ao positivismo jurídico, como na obra "l'analogia nella logica del diritto", publicada em

\footnotetext{
${ }^{1}$ Doutorado em Direito civil-romanístico pela Università degli Studi di Roma "La Sapienza" (2009). Professora no curso de graduação em Direito e no Programa de Pós-Graduação Stricto Sensu em Ciência Jurídica da Universidade do Vale do Itajaí (UNIVALI) e pesquisadora da Fondazione Cassamarca, Itália. E-mail: luciene.dalri@univali.br

2 Esclarecedora a colocação de Miguel Reale (2001, p. 20): "Não concordo, pois, com aqueles que apreciam o pensamento de Norberto Bobbio de maneira estático-formal, pois o fato inegável de sua predileção pelas investigações de claro rigor racionalista não exclui o fato de sua experiência de pensador ter sofrido naturais mutações, desde as suas simpatias iniciais por Husserl e a fenomenologia".
} 
1938, em artigos sobre o costume como fato normativo, a interpretação da lei, e a pessoa como valor do direito.

A partir de 1949, Bobbio entra em uma segunda fase de pesquisa e dedica-se ao estudo crítico do positivismo jurídico, sendo que é a partir de 1954 que ele assume uma clara concepção filosófica neopositivista, analítica e particularmente crítica ao jusnaturalismo. Dentro dessa perspectiva, Bobbio busca o conceito e o valor do direito, por meio da distinção entre fatos e valores; aproximando-se (mesmo que muitas vezes de forma crítica) ao positivismo normativo e em particular à doutrina de Hans Kelsen. (LOSANO, 2007, p. XIX) A pesquisa de Bobbio, em teoria geral do direito, aprofunda-se então no estudo da natureza proposicional das normas, da sua tipologia e da coerência e completude do ordenamento jurídico em sua complexidade.

$\mathrm{Na}$ década de sessenta, observa-se, em alguns escritos de Bobbio, o afastamento em certos pontos da doutrina de Hans Kelsen e a flexibilização de elementos da teoria juspositivista. Tal fato pode ser bem constatado por meio de dois artigos voltados à contribuição de Tullio Ascarelli', e do livro 'Giusnaturalismo e positivismo giuridico', publicado em 1965. (BOBBIO, 1993, p. VII)

A flexibilização de elementos da teoria juspositivista torna-se parte de um processo de mudança de foco, na pesquisa no autor italiano. O posterior desenvolvimento da pesquisa de Bobbio é permeado por um contexto de crise da ciência jurídica e das ciências em geral, onde o autor italiano voltasse para a elaboração de uma teoria funcionalista do direito, complementando a teoria estrutural de Kelsen.

A teoria é desenvolvida principalmente na obra "Da estrutura à função", uma coletânea de textos que evidencia o direito não mais como mero ordenamento coercitivo, mas com função promocional, por meio das sanções positivas, visando "adequar a teoria do direito às transformações da sociedade contemporânea e ao crescimento do Estado social”.(BOBBIO, 2007, p. XI) O autor busca por meio dessa abordagem "suplantar a disparidade entre teoria geral do direito tal qual é e a mesma teoria tal como deveria ser, em um universo social em constante movimento".(BOBBIO, 2007, p. XII)

Neste artigo, propõe-se a análise de alguns escritos de Bobbio, no âmbito da teoria geral do direito, a partir da década de '60, questionando se a flexibilização de alguns aspectos da doutrina positivista, voltando suas pesquisas para a interpretação jurídica, a sociologia, a função social do direito e as normas premiais permitem compreender a concepção do Direito de Bobbio como positivista ou pós-positivista.

Para tanto, faz-se necessário entender o movimento teórico do positivismo jurídico, bem como a relação de Bobbio com essa teoria do direito, denotando noções e conceitos que permitam a resolução do problema

\footnotetext{
${ }^{3}$ Tullio Ascarelli (1903-1959) foi um jurista e professor italiano, judeu e anti-fascista que se ocupou de Direito Comercial e Teoria Geral do Direito. A obra de Ascarelli denota influência do idealismo historicista, por meio de Benedetto Croce. Ascarelli viveu no Brasil entre 1941 e 1946, quando foi professor no curso de Direito da Universidade de São Paulo, posteriormente voltou à Itália onde voltou a exerce à docência. Quanto aos dois artigos citados de Bobbio, são respectivamente de 1964 e 1969: "Tullio Ascarelli”. In "Belfagor", XIX, 1964, p. 411 ss.; e "L'itinerario di Tullio Ascarelli". In Studi in memoria di Tullio Ascarelli. Milão: Giuffré, 1969, vol. 1, p. LXXXIX-CXL.
} 
jurídico em questão, bem como compreender a concepção de pós-positivismo para Bobbio.

\section{POSITIVISMO JURÍDICO E ORDENAMENTO JURÍDICO: KELSEN E BOBBIO}

O termo jus positivum é usado desde o período medieval e concerne a "aquilo que é por convenção ou posto pelos homens", em contraste com o direito natural que é posto por algo além do homem e está presente na natureza. O contexto histórico mais denso que leva à formação do positivismo jurídico encontra-se por meio da formação do Estado, que assume paulatinamente o monopólio da força legítima e do direito, por meio da emanação de leis, enquanto fonte primária do ordenamento jurídico, subordinando todas as outras fontes tradicionais do direito. ${ }^{4}$ A base da teoria juspositivista é expressa de forma clara a partir de Thomas Hobbes, no século XVII, e do pensamento racionalista do século XVIII, muito embora a consolidação dessa concepção como doutrina ocorra apenas no final do século XVIII e início do século XIX.(BOBBIO, 1995, p. 15; BOBBIO, 2001, p. $58 \mathrm{s.}$

O positivismo jurídico é uma concepção que nasce quando 'direito positivo' e 'direito natural' não mais são considerados direito no mesmo sentido, mas o direito positivo passa a ser considerado como direito em sentido próprio. Por obra do positivismo jurídico ocorre a redução de todo o direito a direito positivo, e o direito natural é excluído da categoria do direito: o direito positivo é direito, o direito natural não é direito. A partir deste momento o acréscimo do adjetivo 'positivo' ao termo 'direito' torna-se um pleonasmo mesmo porque, se quisermos usar uma fórmula sintética, o positivismo jurídico é aquela doutrina segundo a qual não existe outro direito senão o positivo. (BOBBIO,1995, p. 26)

O Estado assume a pretensão monista de ser o único a estabelecer o direito, por meio da lei, vinculando a atividade do juiz a essas. $\mathrm{O}$ direito apresenta-se então como fruto da autoridade e emanação de quem detém o poder de legislar e coagir. (BOBBIO, 1995, p. 27 e 36)

Se oggi vi è ancora una tendenza a identificarei il diritto col diritto statuale, essa è la conseguenza storica del processo di accentramento del potere normativo e coattivo che ha caratterizato il sorgere dello stato nazionale moderno. (BOBBIO, 1993, p. 11)

Com essas premissas, o positivismo jurídico distingue-se profundamente, desde o século XIX, do positivismo filosófico e daquele sociológico, sendo marcado por conceber o direito como um fato (e não como um valor), definido pela sua imperatividade (ordem de comando) e coatividade (regulamentação do uso da força), tendo como fonte preeminente a legislação proveniente do Estado (ou de um outro ente, desde que com a

\footnotetext{
4 "Il positivismo giuridico si afferma attraverso la formazione dello Stato moderno che sorge sulle rovine della società feudale pluralistica, e che a poco a poco assume, insieme con il monopolio della forza legittima su un determinato territorio, anche quello della produzione giuridica attraverso la continua emanazione di norme in forma di legge, che diventano la fonte primaria del diritto, cui vengono subordinate tutte le altre fonti tradizionali: la consuetudine, la giurisdizione, la giurisprudenza intesa come il diritto prodotto dai giuristi e il diritto ricavabile dall'osservazione della natura delle cose, il diritto naturale appunto. La consuetudine ha vigore solo in quanto sia riconosciuta dalla legge; il diritto dei giuristi ha valore solo consultivo; il giudice si trasforma a poco a poco in funzionario dello Stato e, in quanto tale, secondo la famosa espressione di Montesquieu, è la "bouche de la loi"; il diritto naturale entra in scena soltanto in caso di lacuna della legge scritta (...) Nonostante la nascita del positivismo teorico in Inghilterra attraverso Hobbes, il diritto inglese ha continuato a essere prevalentemente non legislativo e per tradizione creato dai giudici attraverso l'istituto del precedente obbligatorio" (BOBBIO, 1994).
} 
permissão daquele), a ser interpretada pelo jurista de forma mecanicista, ou seja, considerando mais a declaração presente na norma do que a possibilidade de interpretação criativa e evidenciando o caráter de obediência.

O contexto em que esses elementos são colocados evidencia a necessidade de dar unidade ao conjunto de normas jurídicas aplicadas em sociedade, até então concebidas de forma fragmentária (considerando de forma isolada os diferentes ramos do direito) e, portanto, não sistêmica, gerando incerteza jurídica e permitindo arbitrariedades. Devido a essa necessidade, no início do século XX, desenvolve-se dentro do positivismo jurídico a doutrina do direito como ordenamento jurídico, enquanto conjunto de normas, como se observa na contribuição de Hans Kelsen para a teoria geral do direito. (BOBBIO, 1994)

\section{Hans Kelsen}

Na primeira metade do século XX, Hans Kelsen desenvolve sua teoria do positivismo jurídico normativo, impulsionando seu estudo em toda a Europa.(LOSANO, 2007 , p. XXI ss.) O positivismo normativo de Kelsen é a continuação e refinamento do positivismo jurídico do século XIX, evidenciando a concepção do direito como ordenamento, formando uma estrutura que se manifesta por meio de um conjunto de normas jurídicas coerente e completo, vigente numa sociedade e estabelecendo a organização do aparato coativo.(KELSEN, 1998, p. 26 s.; KELSEN, 2003, p. 26) A unidade do ordenamento jurídico dentro do positivismo jurídico é concebido a partir de um ponto de vista formal, ou seja, concernente ao modo pelo qual as normas são postas, pela autoridade de um único ente (o Estado).(KELSEN, 2003, p. 316 s.)

A coerência e a completude do ordenamento jurídico, por sua vez, ligam-se à unidade enquanto buscam afastar as contradições (antinomias) e colmar as lacunas. (BOBBIO, 1995, p. 131 ss., 198 ss. e 207; BOBBIO, 2007, p. 196) A análise que o positivismo normativo de Kelsen apresenta do direito implica em não se limitar à certos tipos de normas, mas em considerar as características do conjunto de normas que formam o ordenamento jurídico, de maneira essencialmente estrutural.

A análise estrutural evidencia a tentativa de isolamento da ciência do direito em relação à sociedade e às suas ideologias, perseguindo um ideal de torná-la uma ciência autêntica. (KELSEN, 1998, p. XXVIII) O autor austríaco evita o debate sobre a função ou o objetivo do direito, visto que esse varia de acordo com o perfil ideológico do Estado e rompe com a possibilidade de isolamento da ciência do direito em relação à sociedade e suas ideologias. (KELSEN, 2003, p. 26; BOBBIO, 2007, p. 59)

A concepção do direito, no positivismo normativo kelseniano, evidencia a relação entre poder e direito, e mesmo com a busca pelo isolamento de ideologias, apresenta-se favorável à democracia (em base à liberdade e igualdade) por prever a manutenção da ordem jurídica presente na época em que foi lançado e representa uma alternativa à então ciência jurídica e à filosofia política que apoiavam o fascismo e o nazismo. 
Com a segunda guerra mundial e a queda dos regimes totalitários, o positivismo jurídico acaba por perder, porém, seu caráter de alternativa ao fascismo sendo acusado então de conivência com as ditaduras, justamente por não proporcionar o questionamento ético diante das normas impostas. ${ }^{5}$

O positivismo podia assumir um valor liberal quando induzia a respeitar as normas democráticas no momento no qual o poder ditatorial as colocava em perigo, mas depois da consolidação deste poder, o positivismo assumia um valor autoritário porque impunha a aplicação das normas ditatoriais sem colocar-se interrogações éticas. (LOSANO, 2007, p. XXX)

Observa-se então uma crise moral e social na Europa, fruto da consciência das falácias de sistemas ditatoriais e das atrocidades cometidas em nome de objetivos políticos. Nesse contexto, desenvolveu-se um maior interesse de juristas, como Gustav Radbruch ${ }^{6}$ (Alemanha) e Carlo Antoni ${ }^{7}$ (Itália), pelo jusnaturalismo dando ampla força ao renascimento, devido à abertura aos valores morais, em muito afastados pelos regimes totalitários e não abarcados pelo isolacionismo positivista.

\section{Norberto Bobbio}

No período de pós-segunda guerra, mais particularmente a partir de 1949, observa-se a proximidade, muitas vezes de forma crítica, de Bobbio ao positivismo jurídico de Kelsen, levando-o a lecionar um curso sobre a teoria da norma e outro sobre a teoria do ordenamento jurídico, bem como a escrever uma série de artigos sobre o assunto. ${ }^{8} \mathrm{O}$ material mimeografado dos cursos teve várias edições e ganhou fama dentro e fora da Itália, ao ponto de Bobbio ter sido convidado a publicar, na Colômbia, uma obra que reunisse o material dos dois cursos, e assim nasceu a 'Teoría General del Derecho!'

A pesquisa desenvolvida no âmbito da norma e do ordenamento jurídico por Bobbio complementa a teoria positivista de Kelsen, ao afirmar que a teoria do "ordenamento jurídico constitui uma integração da teoria da norma jurídica”.(BOBBIO,1997, p. 22) O autor italiano evidencia a dificuldade em dar uma definição do direito que parta da concepção da norma jurídica de forma isolada, e considera que "uma definição satisfatória do direito

\footnotetext{
${ }^{5}$ As acusações ao positivismo jurídico em termos de ideologia "responsável pela concepção estatolátrica, pelo princípio de obediência incondicional à lei do Estado e pelas nefastas consequências que isso produziu nos regimes totalitários" são expostas e rebatidas por Bobbio (1995, p. 233 ss). Ver também LOSANO, 2007, p. XXX.

${ }^{6}$ RADBRUCH publicou o artigo "Gesetzliches Unrecht und übergesetzliches Recht", na Süddeutsche Juristenzeitung de 1946; o artigo é retomado em Rechtsphilosophie, dirigida por E. WOLF KOEHLER, Stuttgart, 1956, pp. 347-357, em italiano publicado como RADBRUCH, Gustav. Propedeutica alla filosofia del diritto. Torino: Giapichelli, 1959, p. 233. Ver sobre o tema Losano (2007, p. XXXV) e Bobbio (1994).

${ }^{7}$ Carlo Antoni publicou na Itália a obra "La restaurazione del diritto di natura" (Venezia: Neri Pozza, 1959).

${ }^{8}$ Segundo Losano, o fruto mais evidente da influência de Kelsen sobre Bobbio é a visão do direito como ordenamento (hierarquizado) de normas. (LOSANO, 2007, p. XXIV). No mesmo sentido Miguel Reale "O importante no kelsenismo, no seu entender (o de Bobbio), é a visão do ordenamento jurídico como um escalonamento normativo, válido de per si, e não como criação do poder estatal". REALE, Miguel. Legados de Norberto Bobbio, p. 133 ss., disponível no site www.academia.org.br/abl/media/prosa13.pdf, acessado em 22/08/2014.

9 No Brasil, a obra foi publicada em dois livros: Teoria da norma jurídica e Teoria do ordenamento jurídico. LOSANO, 2007, p. XXIV.
} 
só é possível se nos colocarmos do ponto de vista do ordenamento jurídico".(BOBBIO, 1997, p. 22)

Nunca será demais insistir no fato de que foi com Kelsen que, pela primeira vez a teoria do direito orientou-se definitivamente para o estudo do ordenamento jurídico como um todo, considerando como conceito fundamental para uma construção teórica do campo do direito não mais o conceito de normas, mas o de ordenamento, entendido como sistema de normas. (BOBBIO, 2007, p. 195)

Nesse sentido e considerando que "Só em uma teoria do ordenamento - este era o ponto a que importava chegar - o fenômeno jurídico encontra sua adequada explicação", pode-se conceber a sanção, a validade e a eficácia como elementos constitutivos do direito. (BOBBIO, 1997, p. 28)

Quando se fala em uma sanção organizada como elemento constitutivo do direito, nos referimos não às normas em particular, mas ao ordenamento normativo tomado em seu conjunto, razão pela qual dizer que a sanção organizada distingue o ordenamento jurídico de qualquer outro tipo de ordenamento não implica que todas as normas daquele sistema sejam sancionadas, mas somente que o são em sua maioria.' ( ...) O mesmo se diga da eficácia. Se considerarmos a eficácia como um caráter da norma jurídica, encontramo-nos, em certo ponto, diante da necessidade de negar o caráter de norma jurídica a nomas que pertencem a um sistema normativo dado (enquanto legitimamente produzidas). Elas são válidas, mas não eficazes, porque jamais foram aplicadas (como é o caso de muitas normas de nossa Constituição). (...) O problema da validade e eficácia, que gera dificuldades insuperáveis desde que se considere uma norma do sistema (a qual pode ser válida sem ser eficaz), diminui se nos referirmos ao ordenamento jurídico, no qual a eficácia é o próprio fundamento da validade. (BOBBIO, 1997, p. 29)

A mudança do ângulo de visão, no que concerne ao direito, conforme denotada acima e proporcionada por meio da concepção de ordenamento jurídico (enquanto conjunto de normas), permite, segundo o autor, uma inovadora, mais ampla e coerente concepção de direito.(BOBBIO, 1997, p. 31) A concepção do ordenamento jurídico influenciada pelo modelo de Kelsen aponta para os mesmos aspectos de unidade, coerência e completude, muito embora se diferencie em relação à preocupação de contextualização histórica de conceitos e problemas colocados pela experiência normativa.(LAFER, 2001, p. 76)

O ordenamento, enquanto conjunto de normas evidencia a pluralidade como parte do conjunto e consequentemente surge um importante problema concernente à "relação das diversas normas entre si". Essa relação deve ser então considerada à luz da unidade do ordenamento jurídico (se as normas constituem uma unidade e de que modo a constituem), que pressupõe uma norma fundamental e implica na análise das fontes do direito e no problema da hierarquia das normas dentro do ordenamento.(BOBBIO, 1997, p. 34) A característica de unidade do ordenamento jurídico implica em concebê-lo como sistema, entendido como conjunto em que as normas tenham um relacionamento de coerência e, portanto compatibilidade entre si, excluindo antinomias.(BOBBIO, 1997, p. 71) A característica de completude, por sua vez, implica na existência de previsão normativa para cada caso, inexistindo lacunas no ordenamento jurídico. (BOBBIO, 1997, p. 115 s.)

Ao tratar das relações entre os ordenamentos jurídicos, e consequentemente do pluralismo jurídico, Bobbio volta-se à teoria do historicismo jurídico, bem como àquela institucional do Direito (de Santi Romano), muito embora de forma mais aprofundada e evidenciando certa influência. (BOBBIO, 1982, p. 163 s.) 
A teoria institucional, assim como o próprio positivismo, é contextualizada historicamente pelo autor torinês que a identifica como uma reação ao estatalismo (típico do positivismo), sendo uma das formas por meio das quais os teóricos do direito e da política tentaram resistir à invasão do Estado. (BOBBIO, 1993, p. 11)

Bobbio entende que as duas teorias (o direito enquanto organização/instituição e o pluralismo jurídico) são independentes e é crítico à concepção de Santi Romano de direito como "organização" (ROMANO, 2008, p. 76 ss.), alegando que a teoria seria pouco elaborada e não clara quanto ao uso do termo, muito embora reconheça seu relevo no que concerne à concepção do direito como conjunto coordenado de normas. (BOBBIO, 1977, p. $25 \mathrm{ss}$.)

Para nós, a teoria da instituição teve o grande mérito, mesmo prescindindo de seu significado ideológico, que não pretendemos discutir, de pôr em relevo o fato de que se pode falar de direito onde há um complexo de normas formando um ordenamento e, portanto, o direito não é norma, mas conjunto coordenado de normas; concluindo, uma norma jurídica não se encontra nunca sozinha, mas é ligada a outras normas com as quais forma um sistema normativo. Graças também à teoria da instituição, a teoria geral do direito veio evoluindo cada vez mais da teoria das normas jurídicas à teoria do ordenamento jurídico, e os problemas que vêm se apresentando aos teóricos do direito são cada vez mais conexos à formação, à coordenação e à integração de um sistema normativo.

O reconhecimento à teoria de Santi Romano demonstra-se também no que concerne à teoria do pluralismo jurídico e reconhece sua necessidade dentro do contexto social, por ampliar o horizonte do jurista além dos confins do Estado. (BOBBIO, 2001, p. 28 ss.)

O sucesso da teoria pluralista resultou do fato de que ela oferecia uma representação mais satisfatória da realidade social, exatamente no momento em que o fervilhar das forças sociais, o qual se seguiu à pressão da "questão social", ameaçava lançar pelos ares - e em alguns países já havia acontecido - a tampa do Estado. Romano apreendeu muito bem essa realidade quando observou que, se nos últimos séculos houve um continuo processo de estatização da sociedade, no presente encontrávamo-nos, presumivelmente, diante do processo inverso, que poderíamos denominar de socialização do Estado.

A influência de Santi Romano sobre Bobbio delineia-se, portanto, não tanto na consideração do direito enquanto ordenamento, essa influência é atribuída à Kelsen (BOBBIO, 1982, p. 19 ss.; BOBBIO, 2007, p. 195), mas principalmente em uma fase posterior, dentro de uma tendência de socialização do Estado e do direito, evidenciando a pluralidade de ordenamentos jurídicos e sem se deixar levar pela hipótese de reabsorção do Estado pela sociedade. (BOBBIO, 2001, p. 30 s.)

Muito embora o interesse de Bobbio pelo positivismo de Kelsen (e a influência do autor austríaco sobre as suas posteriores fases de pesquisa), o autor italiano não escapou ao interesse por valores morais (típico de sua época). Nesse sentido, Bobbio movimentou-se dentro de uma progressiva mudança de paradigmas, como se observa nos artigos sobre Tullio Ascarelli (BOBBIO, 1964, p. 411 ss.; BOBBIO, 1969, vol. I, p. LXXXIX-CXL) e no livro Giusnaturalismo e positivismo giuridico (1965), bem como na coletânea de artigos das décadas de '60 e '70 que resultou na obra Dalla struttura alla funzione (1977), nos quais Bobbio evidencia a crise do positivismo jurídico. (BOBBIO, 1995, p. 233) 
A visão crítica ao positivismo jurídico é aguçada pela concepção de mudança do Estado e da função do direito e pela aproximação à teoria do realismo jurídico (evidenciando mais a efetividade da norma jurídica do que a sua validade), bem como pela difícil relação com os valores morais, refletindo uma aproximação também à sociologia do direito.(LOSANO, 2007, p. XXXII) A concepção positivista de Bobbio associa-se então e cada vez mais a um direito social, enquanto "subsistema do sistema global da sociedade", evidenciando a pluralidade de fontes extra-legislativas do direito (com a crise do sistema proposto pelo positivismo normativo) e a sua função social, aproximando-o das ciências sociais. Para Bobbio, o papel da sociologia do direito seria justamente de auxiliar a teoria do direito com relação ao problema das funções do direito.

\section{O JURISTA E A INTERPRETAÇÃO DO DIREITO: A INFLUENCIA DE TULLIO ASCARELLI}

A ampliação das concepções de Bobbio, quanto a alguns pontos da doutrina do positivismo normativo de Kelsen, ocorreu, como visto, desde a década de '60, e pode ser observada no que concerne à função do direito, à interpretação do direito e à função criadora do jurista, por meio da pesquisa (e influência) da obra de Tullio Ascarelli. ${ }^{10}$

A fecunda influência de Ascarelli sobre Bobbio pode ser bem entendida por meio da comum sensibilidade de ambos os juristas no que concerne à sociologia, à política e à filosofia do direito. (BOBBIO, 2007, p. 246) A concepção de Ascarelli, do direito como fenômeno histórico, remonta, por sua vez, à influência do idealismo historicista de Benedetto Croce e que na Itália é um dos aspectos de reação ao positivismo jurídico e que acabou por colocá-lo em crise.

Um dos temas dominantes na filosofia jurídica inspirada no idealismo historicista foi o da identidade, ou, se preferirmos, da distinção dialética entre momento da criação e momento da interpretação do direito em nome da unidade do movimento histórico no qual a abstração da norma se converte continuamente na concretização da sua atuação. (BOBBIO, 2007, p. 220; REALE, 1979, p. 196)

Algumas importantes influências para a concepção sociológica, criadora e axiológica que Ascarelli apresenta da atividade do jurista, desde as obras da juventude, são de fonte norte-americana, como os jusfilósofos

\footnotetext{
${ }^{10}$ Os dois artigos de Bobbio sobre Ascarelli foram escritos nos anos de 1964 e 1969 e tem como principais referências (ver também Id., p. 241): Appunti di diritto commerciale (Roma, 1936) e no artigo Lídea del codice nel diritto privato e la funzione dellinterpretazione, publicado inicialmente no volume Problemas das sociedades anônimas e direito comparado (São Paulo: Saraiva, 1945); Funzioni economiche e istituti giuridici nella tecnica dellinterpretazione e o prefácio da coletânea Studi di diritto comparato e in tema dinterpretazione (Milano: Giuffré, 1952). Como envidencia Reale, "Apesar do grande amor dedicado à teoria da interpretação, e o valor das contribuições que nos legou, tal com o procurarei lembrar em largos traços, ASCARELLI não nos escreveu um tratado sistemático da matéria, preferindo focalizá-la em diversos estudos, que, no entanto, guardam entre si unidade substancial". REALE, Miguel. A Teoria da Interpretação Segundo Tullio Ascarelli, in Revista da Faculdade de Direito da Universidade de São Paulo, v. 74 (1979) p. 196. Disponível em http://www.revistas.usp.br/rfdusp/article/view/66878/69488, acesso em 25/09/2015. Trata-se de conferência proferida por Miguel Reale na Sala da Congregação dos Professores da Faculdade vol.10, no. 01, Rio de Janeiro, 2017.pp.24-43 
Oliver W. Holmes, Roscoe Pound e Benjamin Cardoso. (REALE, 1979, p. 197)

Em sua pluralidade de influências, Ascarelli proporciona à Bobbio a visão de um ordenamento jurídico composto não apenas por leis, mas também por interpretações que permitem a integração do conjunto de normas e ainda fomentam a sua dinâmica. (REALE, 1979, p. 195)

A interpretação tem, todos o afirmam, uma função no próprio desenvolvimento do direito. Independentemente da interpretação não há, realmente, sistema jurídico, pois que cada sistema, assente ele em leis, costumes ou jurisprudência, precisa sempre e continuamente ser aplicado, desenvolvido e adaptado pela interpretação. (ASCARELLI, 2007, p. 147)

A interpretação jurídica apresenta papel importantíssimo na visão de Croce e de Ascarelli, sendo evidenciada por Bobbio "como criação contínua no processo de adaptação do texto à realidade histórica em movimento".(BOBBIO, 2007, p. 220) O trabalho doutrinário e jurisprudencial é apresentado então, na doutrina de Ascarelli, como indispensável para a integração do ordenamento jurídico e a sua adaptação às necessidades da vida, denotando por meio da 'dinâmica jurídica' a concepção de um direito vivo e funcional.(BOBBIO, 2007, p.

A visão de uma nova função do jurista implica em superar a concepção do papel do "jurista como conservador e transmissor de um coro de regras já dadas" e entende-lo como "criador, ele mesmo, de regras que transformam - a ele integrando-se e inovando-o - o sistema dado, do qual não é mais apenas receptor, mas também colaborador ativo e, quando necessário, crítico".(BOBBIO, 2007, p. 37) Tal fato não implica, porém, na inversão dos papéis entre jurista e legislador, pois ao abrir espaço à sociologia, não se perde de vista a diferença entre ponto de vista sociológico e ponto de vista normativo. De fato, observa Bobbio que "A discussão de Ascarelli sobre a interpretação movimenta-se sempre entre dois polos, o da criatividade e o da continuidade". (BOBBIO, 2007, p. 255)

L'interprete (in ciò contrapponibile al legislatore) trova un limite alla sua discrecionalità in quel criterio di continuità pel quale la norma interpretativamente posta deve essere riconducibile ad altra data, continuità che suole appunto esprimersi parlando della dichiaratività dell'interpretazione. Ma appunto perchè si trata di continuità e non di deduzione logica, la sua ricorrenza si identifica con l'accetazione stessa del risultato come risultato interpretativo. Questa accettazione segna il limite del successo interpretativo ed è attraverso questa accettazione che finiscono poi per concorrere la norma dettata e quella socialmente vigente. (ASCARELLI, 1959, p. 86)

Deverá o intérprete, de um lado, conservar a continuidade da solução com o direito vigente - e, já por isso, é ele 'intérprete' e não legislador - na excrupulosa observância do princípio de 'legalidade', de outro lado, entretanto, desenvolver o direito nas suas novas aplicações.

A tarefa da interpretação não pode ser substituída pelo contínuo recurso à obra legislativa, que perde o seu caráter quando chega a ficar hipertrófica, ou quando perigosamente passa a exercitar uma função interpretativa que é, ao contrário, privativa da jurisprudência auxiliada pela doutrina, do juiz auxiliado pelos advogados. (ASCARELLI, 2007, p. 147)

de Direito da Universidade de São Paulo, a 31 de outubro de 1979, às 21 horas, em memória de Tullio Ascarelli, no $20^{\circ}$ aniversário vol.10, no. 01, Rio de Janeiro, 2017.pp. 24-43 
As ideias de Ascarelli facilitaram o amplo contato com a experiência jurídica norte-americana, em ambiente italiano e brasileiro, reforçando-se no contexto jurídico pós-segunda-guerra, quando a cultura jurídica dos Estados Unidos se tornou um ponto de referência para os demais juristas europeus. Tal fato tornava frequente a reflexão sobre o modelo europeu de Civil Law diante das características do modelo de Common Law. (LOSANO, 2010, p. 245). Nessa perspectiva, a concepção anglo-americana do judge made law teria permitido a expansão na Europa da tarefa criativa do juiz, no âmbito das normas jurídicas, abarcando também máximas da experiência e de princípios gerais.

Essa corrente pode ser associada à noção de sistema por meio de seus estudos sobre a lacuna legislativa: de fato, todo discurso sobre a lacuna pode ser lido como um discurso ex negativo sobre o sistema. Essa perspectiva impõe, por um lado, encontrar soluções práticas não contidas em claras letras no direito positivo e, por outro, confia ao juiz a tarefa de preencher a lacuna, exaltando assim sua função criadora do direito. (LOSANO, 2010, p. 246)

A definição da função do jurista, mesmo sendo variável conforme o modelo jurídico, a situação social, e a concepção do direito (e sua relação com a sociedade), nos ordenamentos jurídicos europeus amplia-se, portanto com a influência do Common Law. A realidade na qual se enquadra o jurista "no universo dos países de estrutura econômico-capitalista e de primazia do regime liberal-democrático" é contextualizado em um sistema aberto, ou seja, em uma sociedade em transformação, que apresenta uma ideologia do direito como reflexo da sociedade. Tal concepção implica em uma ciência do direito livre inovadora e realista, onde o direito não é um sistema de regras postas e estáticas, mas um conjunto de regras dinâmicas, em movimento.

A função atribuída ao jurista, de interpretação e, portanto, de movimento na adequação do direito às necessidades sociais, permite à Ascarelli promover a conscientização do jurista, no que tange a sua função em sociedade. A concepção de 'função do jurista' deriva do mesmo pressuposto da 'função prática da ciência do direito', proclamada pelo autor e encontra pleno desdobramento na obra de Bobbio após os anos 60, com a sua paulatina pesquisa sobre o funcionalismo jurídico.

Como manifesta Miguel Reale:

Quando NORBERTO BOBBIO dá a um de seus livros o título de Struttura e funzione del Diritto, e nela inclui um estudo sobre o itinerário de Ascarelli, tenho a impressão de que o ponto de partida ou elemento inspirador dessa obra foram os estudos de seu compatriota e amigo. (REALE, 1979, p. 197)

Com uma abordagem da ciência do direito voltada para a função prática e dentro de um contexto histórico, Ascarelli evidenciou a sua concepção de "funcionalismo jurídico", em 1946, em uma conferência na Escola de Sociologia e Política da Universidade de São Paulo e que posteriormente foi publicada na Itália sob o título Funzioni Economiche e istituti giuridici nella tecnica dell'interpretazione. ${ }^{11}$

\footnotetext{
de seu falecimento, reproduzida segundo gravação, revista pelo Autor.

${ }^{11}$ ASCARELLI, 1946 e 1949. JANSEN, 2003, p. 19. O autor brasileiro indica como outras obras de Tullio Ascarelli e que abordam o tema: Funzioni Economiche e instituti giuridici nella tecnica dell'interpretazione, in Saggi Giuridici, Milão, Giuffrè, 1949, p. 83 a 106 ) com argumentos que desenvolveu, mais tarde, no prefácio à coletânea Studi di diritto comparato e in tema d'interpretazion (e vol.10, no. 01, Rio de Janeiro, 2017.pp. 24-43 
Em continuidade a essa linha, no ensaio Norma giuridica e Realtà sociale Ascarelli (1959, p. 85 ss.) manifesta-se de forma clara sobre a estrutura e a função dos institutos jurídicos e é nessa linha que Bobbio define o objeto da ciência jurídica ou do trabalho do jurista como não sendo tanto as normas, mas principalmente a vida social sujeita às normas. (BOBBIO, 2007, p. 40 ss.)

\section{A FUNÇÃO DO ESTADO SOCIAL E DO DIREITO}

Com a análise crítica do positivismo normativo e fortemente influenciado pela concepção de função e interpretação do direito, também diante do Estado Social, o interesse de Bobbio desloca-se para a filosofia política e ele passa a lecionar na Faculdade de Ciências Políticas.

A forte concepção política e sociológica do direito presente em Norberto Bobbio evidencia as mudanças jurídicas em consequência das mudanças ocorridas quanto às funções do Estado.(BOBBIO, 2007, p. 33) Nesse sentido, ao tratar da função promocional do direito, Bobbio dá sequência às reflexões de Genaro R. Carrió (1966, p. 141-55) no que tange à profunda transformação que deu origem ao Estado Social e a consequente ampliação das funções do Estado, não mais voltado apenas para uma concepção liberal de não intervenção e manutenção da segurança coletiva, mas então incumbido de amenizar as desigualdades sociais.

Tomando essa observação como ponto de partida, proponho-me a examinar um dos aspectos mais relevantes $-\mathrm{e}$ ainda pouco estudados na própria sede da teoria geral do direito - das novas técnicas de controle social, as quais caracterizam a ação do Estado social dos nossos tempos e a diferenciam profundamente da ação do Estado liberal clássico: o emprego cada vez mais difundido das técnicas de encorajamento em acréscimo, ou em substituição, às técnicas de desencorajamento. É indubitável que essa inovação coloca em crise algumas das mais conhecidas teorias tradicionais do direito que se originam de uma imagem extremamente simplificada do direito. Refiro-me, em particular, à teoria que considera o direito exclusivamente o ponto de vista da sua função protetora e àquela que o considera exclusivamente do ponto de vista da sua função repressiva. É desnecessário acrescentar que, com frequência, as duas teorias encontram-se sobrepostas: o direito desenvolve a função de proteção em relação aos atos lícitos (que podem ser tanto atos permitidos quanto obrigatórios) mediante a repressão dos atos ilícitos. (BOBBIO, 2007, p. 2)

Uma das importantes diferenciações entre Kelsen e Bobbio está justamente na evidenciação e importância atribuída às sanções positivas e à função promocional do direito. Kelsen concebe o direito nos moldes de uma teoria estrutural, que pouco evidencia a função do direito e preponderantemente o define por meio de sua estrutura de forma limitada à ameaça ou à sanção. A teoria positivista de Kelsen mesmo considerando a existência das sanções positivas, as concebe como de caráter secundário, visto que a essência dos sistemas jurídicos seria de caráter coercitivo. (KELSEN, 2003, p. 26 e 37)

Bobbio foi além desse molde e propôs um ponto de vista histórico e funcional, voltado para a finalidade

continuou a desenvolver in Dispute metodologiche e contrasti di valutazioni (1953); Interpretazione del diritto e studio del diritto comparato (1954); Norma giuridica e realtà sociale (1955); Giurisprudenza costituzionale e teoria dellinterpretazione e Ordinamento giuridico e processo economico (1958). 
do direito dentro de um Estado social não apenas como forma de controle, mas também de direção social. (BOBBIO, 2007, p. 77; LOSANO, 2007, p. XXXVIII) A concepção funcional manifesta-se, portanto não apenas na função repressiva dos comportamentos violadores da norma, mas também na crescente função do Estado, exercida por meio do direito, de promotor do bem-estar e da orientação aos comportamentos desejados por meio de normas premiais. Bobbio evidenciou no ordenamento jurídico, portanto, o "direito premial" como complementar do "direito penal", enquanto instrumento de orientação de condutas. De fato, a função promocional do direito é um dos elementos de superação ou complementação de Bobbio ao positivismo normativo de Kelsen, evidenciando uma concepção sociológica e histórica do direito, de certa forma já presente em Jhering.

A evidenciação da mudança de paradigmas do direito devido ao Estado Social leva Bobbio a analisar a teoria de Hayek (1966, p. XXXI) que denota particularmente o aumento das normas de organização (ou secundárias) dentro do ordenamento jurídico. As normas de organização são aquelas pelas quais o Estado regula a ação dos próprios órgãos bem como a formação de grandes organizações (tanto dentro da estrutura do Estado, quanto da sociedade civil), o aumento dessas normas reflete o aumento das funções estatais, presentes no Estado assistencial. Em paralelo ao crescimento de tais normas ocorre o crescimento das normas positivas e das sanções positivas.

A importância dada ao vertiginoso aumento das normas de organização, o qual caracteriza o
Estado contemporâneo, não coloca em crise, necessariamente, a imagem tradicional do
direito como ordenamento protetor-repressivo. Ao contrário, isso se dá pelo que observei
inicialmente: no Estado contemporâneo, torna-se cada vez mais frequente o uso das técnicas
de encorajamento. Tão logo comecemos a nos dar conta do uso dessas técnicas, seremos
obrigados a abandonar a imagem tradicional do direito como ordenamento protetor-
repressivo. Ao lado desta, uma nova imagem toma forma: a do ordenamento jurídico como
ordenamento como função promocional. (BOBBIO, 2007, p. 11)

Uma das diferenças entre os dois tipos de ordenamento acima citados, é que ao ordenamento de tipo protetor-repressivo interessa principalmente os comportamentos socialmente não desejados, visando o seu combate, enquanto que ao ordenamento de tipo promocional interessa principalmente os comportamentos socialmente desejáveis, visando sua realização. $\mathrm{O}$ ordenamento repressivo visa tornar a ação não desejada socialmente impossível, difícil e/ou desvantajosa, enquanto o ordenamento promocional visa tornar a ação desejada necessária, fácil e vantajosa. (BOBBIO, 2007, p. 15) O agir do Estado pode ocorrer então no encorajamento "sobre as consequências do comportamento ou sobre as modalidades, sobre as formas, sobre as condições do próprio comportamento". Tal fato observa-se no ordenamento promocional por meio das leis de incentivo que permitem a facilitação da ação (ex.: subvenção) e a sanção positiva (ex:: isenção fiscal).

Do ponto de vista estrutural, Bobbio denota que a medida repressiva (desencorajamento) apresenta uma ameaça, enquanto a promocional (encorajamento) apresenta uma promessa e que tais concepções denotam relações distintas baseadas na inversão do sujeito ativo e passivo da relação obrigacional: como exemplo, quando 
o indivíduo pratica um comportamento desencorajado por uma ameaça do Estado, aquele que ameaçou (o Estado) tem o direito de executar a ameaça, enquanto que se o indivíduo pratica um comportamento encorajado por uma promessa (do Estado), ele tem o direito de que a promessa seja mantida (pelo Estado). Tais concepções denotam de um ponto de vista funcional a busca por conservação (inércia, não realização de certos comportamentos) ou mudança social (ação, transformação).

Isso posto, é preciso, de imediato, acrescentar que o reconhecimento da importância do direito promocional não é, em absoluto, incompatível com a consideração instrumental do direito, própria da teoria kelseniana: o uso de sanções positivas, ou, de qualquer forma, de incentivos econômicos, nada mais é que uma técnica específica de organização social. Mesmo depois de termos percebido que o direito não se limita a reprimir, mas estimula ou promove, podemos continuar a afirmar, como faz Kelsen, que o direito é um meio, e não um fim. Quando chegamos, ainda, a sustentar que o direito é a organização não apenas do poder coativo, mas também do poder econômico, não escapamos de um determinado modo de entender a especificidade do direito, que consiste precisamente em considerá-lo uma forma de 'organização social'. Contudo, chegados neste ponto, somos reconduzidos, novamente, da análise funcional à estrutural. (BOBBIO, 2007, p. 77)

As duas concepções da função do direito podem e devem ser vistas como complementares, reconhecendo no ordenamento jurídico tanto a função coativa, quanto a função promocional e evidenciando, portanto, o direito (do ponto de vista funcional) "como forma de controle e de direção social”. (BOBBIO, 2007, p. 209)

A visão de Bobbio é bastante clara sobre a importância do positivismo normativo no saggio Hans Kelsen, publicado na Rivista internazionale di filosofia del diritto, em 1973 e republicado posteriormente sob o título de "Estrutura e função do direito de Kelsen". ${ }^{2}$ No citado texto, o autor torinês, após indicar o caráter de complementaridade entre função protetivo-repressiva e função promocional do direito, afirma

Isso posto, é preciso acrescentar, ainda, que as mudanças ocorridas na função do direito não anulam a validade da análise estrutural tal como foi elaborada por Kelsen. O que ele disse acerca da estrutura do ordenamento jurídico permanece perfeitamente de pé, mesmo depois dos desenvolvimentos mais recentes da análise funcional. A construção do direito como sistema normativo dinâmico não é minimamente abalada pelas revelações que dizem respeito ao fim do direito. Para ela, uma norma é jurídica sempre que tenha sido produzida nas formas previstas, isto é, em conformidade com outras normas do ordenamento, em particular aquelas que regulam a produção das normas do sistema. (BOBBIO, 2007, p. 209)

A concepção do autor evidencia sua ideologia política, social-democrática de tradição liberal, mas ao mesmo tempo denota a necessidade de compreensão do direito e de sua função como instrumento de um Estado Social.

\section{DO POSITIVISMO JURÍDICO AO PÓS-POSITIVISMO: A ADAPTAÇÃO ȦS NOVAS NECESSIDADES}

\footnotetext{
${ }^{12} \mathrm{O}$ texto indicado foi republicado posteriormente nas obras "Dalla struttura alla funzione", 1977, e "Diritto e potere. Saggi su Kelsen”, 1992, p. 65/87.
} 
A crítica e a flexibilização de certos elementos do positivismo jurídico, por parte de Bobbio, ganha ainda mais força no tempo e é evidenciada de maneira ainda mais objetiva no artigo Giusnaturalismo e giuspositivismo, publicado na Enciclopedia delle scienze sociali em 1994. A crítica do autor italiano evidencia que o questionamento do positivismo jurídico a partir da segunda metade do século XX não é fruto do renascimento do jusnaturalismo (LOSANO, 2010, p. 239 ss.), em um jogo de contraposição que ocorre desde o início da modernidade (BOBBIO, 1994), mas trata-se de limitações internas da própria doutrina, em relação aos modos de produção do direito:

Le ragioni del positivismo giuridico, così com'era stato concepito sino allora, sono state messe in questione non dalla solita rinascita del diritto naturale, ma da profondi mutamenti dello Stato di diritto e della società sottostante, che hanno a poco a poco resa sempre più inadeguata la raffigurazione dello Stato legislatore e del giudice-esecutore, sulla quale si era venuta formando dall'inizio del secolo scorso la teoria giuspositivistica.

Se di una crisi del positivismo giuridico si può parlare, questa nasce all'interno stesso della dottrina, di fronte alla quale non si erge più un nuovo o rinnovato giusnaturalismo, ma se mai si affaccia una nuova concezione del diritto positivo, costretto per il mutamento dei modi di produzione del diritto ad abbandonare o attenuare alcune delle tesi più tipiche, trasformatesi in dogmi, come quelle dell'onnipotenza del legislatore, dell'unità, completezza, coerenza dell'ordinamento, della validità formale delle norme, della imperatività e coattività del diritto. (BOBBIO, 1994)

O autor italiano indica então a contribuição de Ronald Dworkin, estadunidense e aluno de Herbert L. A. Hart, na correção do positivismo jurídico, por meio da obra Taking rights seriously (London 1977), onde se critica a tese positivista do direito como conjunto de regras (rules) e desconsidera os critérios com os quais os juízes aplicam o direito, como os princípios (principles), que expressam uma exigência geral de justiça. ${ }^{13}$ Bobbio entende a inovação de Dworkin como a ampliação da área dos critérios em base aos quais os juízes aplicam a justiça:

Più che di un'alternativa al diritto positivo si tratta di un allargamento dell'area dei criteri in base ai quali i giudici rendono giustizia, un allargamento, tra l'altro, che abbraccia principî generalissimi della condotta, di cui lo stesso positivismo giuridico non ha mai rifiutato di tenere conto, se pure in ultima istanza. (BOBBIO, 1994)

O positivismo jurídico em sentido estrito teria então sido colocado em xeque pela positivação de princípios gerais, inspirados nos ideais de liberdade e justiça, em constituições rígidas, tornando-se direito positivo e sendo posto acima das leis ordinárias.

A inserção dos princípios nos textos constitucionais fez com que o positivismo jurídico tradicional perdesse a certeza do direito, enquanto valor que pretendia ser absoluto, por conta de seu caráter subjetivo a ser

\footnotetext{
${ }^{13}$ O pós-escrito de Hart (O conceito de Direito. São Paulo: WMF Martins Fontes, 2012, p. 347 s.), em pleno debate com a teoria de Dworkin, denota também certo reconhecimento entre direito e moral: "a existência e o teor do direito podem ser determinados consultando-se as fontes sociais do direito (por exemplo, a legislação, as decisões judiciais e os soctumes sociais), sem referência à moral, exceto quando o próprio direito assim identificado tiver incorporado critérios morais para sua identificação", mais adiante Hart reafirma a moral quanto às limitações do que pode ser considerado direito, onde "não somente os princípios mais sólidos que se adaptem ao direito, mas também aqueles considerados moralmente sólidos segundo os parâmetros daquilo que Dworkin vol.10, n. 01, Rio de Janeiro, 2017.pp. 24-43 
interpretado pelos juristas. Tal fato não implica no renascimento do jusnaturalismo, mas em algo diverso a ser identificado como pós-positivismo.

$\mathrm{Ma}$ anche sotto questo aspetto più che della rinascita di un nuovo giusnaturalismo si dovrebbe parlare, in forma ancora vaga che attende di essere precisata in seguito alle trasformazioni in corso delle società politicamente ed economicamente più avanzate, di postpositivismo, dove il 'post' sta a indicare per ora semplicemente che l'antico dibattito tra giusnaturalisti e positivisti non può più essere posto nei termini abituali, ma attende nuovi protagonisti e nuove idee. (BOBBIO, 1994)

A concepção que Bobbio apresenta do pós-positivismo é de fruto de uma dinâmica de desenvolvimento do positivismo jurídico, colocado em crise diante de mudanças do Estado de Direito e da sociedade, e levando à revisão da figura do Estado legislador e do juiz executor. Trata-se de conceber o "pós" como um movimento interno da própria doutrina positivista, diante das necessidades delineadas pelo contexto político e social, e que amplia os critérios de aplicação do direito abarcando a sua concepção funcional e permeável, por meio de princípios, aos ideais de liberdade e justiça.

\section{O PÓS-POSITIVISMO: ENTRE FERRAJOLI E LOSANO}

O problema que fomenta o presente artigo, quanto ao entendimento de Bobbio como positivista ou pós-positivista, implica em considerar a concepção de pós-positivismo, que não é pacífica na doutrina. Nesse sentido, traz-se as concepções de Ferrajoli e de Losano, professores italianos, filósofos do direito e que tem suas formações intelectuais particularmente ligadas às pesquisas de Bobbio, por terem sido seus alunos.

Ferrajoli é um jurista que se filia ao juspositivismo, por meio da influência de Kelsen e de Bobbio, propondo como uma das teorias positivitas o "garantismo".(FERRAJOLI, 2012, p. 792) No Prólogo da obra Derecho y razón, Bobbio (BOBBIO, 2005, p. 17) evidencia que Ferrajoli, enquanto teórico geral do direito, pertence à família dos positivistas ("en la tradición de Kelsen, Hart y positivismo italiano de este último cuarto de siglo"), no mesmo sentido em que Ferrajoli apresenta sua teoria, construída dentro da tradição filosófico-jurídica de inspiração positivista.( FERRAJOLI, 2005, p. 868)

$\mathrm{Na}$ obra Garantismo, hermenêutica e (neo) constitucionalismo, Ferrajoli entende que o pós-positivismo tem como linha distintiva

A configuração como princípios ético-políticos de grande parte das normas constitucionais, em especial dos direitos fundamentais, e a adoção de uma distinção forte, qualitativa e estrutural, entre princípios e regras, sendo os primeiros objetos de ponderação e as segundas de aplicação mediante subsunção. (FERRAJOLI; STRECK; TRINDADE, 2012, p. 17)

A referência ao pós-positivismo ocorre de forma clara, às teorias de Dworkin e de Alexy, também no artigo El constitucionalismo entre principios y reglas, publicado na DOXA (n. 35, 2012) entendendo-os como

chamou de "moral de fundo" (background morality), podem de fato oferecer limites ou restrições morais ao que pode ser considerado direito”. 
tendencialmente neoiusnaturalistas.

Pospositivista y tendencialmente neoiusnaturalista, según la cual los principios morales de justicia introducidos en las constituciones —objeto de ponderación y no, como las reglas, de aplicación mediante subsunción - habrían restablecido la conexión premoderna de derecho y moral y puesto fin a la separación entre las dos esferas producida en el derecho moderno con la afirmación del paradigma positivista. (FERRAJOLI, 2012, p. 792)

A concepção de pós-positivismo de Ferrajoli não permite entender a contribuição de Bobbio quanto ao funcionalismo jurídico e à sociologia do direito como pós-positivista, mas como paleo-positivista, visto que o autor garantista também não faz distinção quanto aos diferentes períodos de pesquisa de Bobbio. (FERRAJOLI, 2012, p. 791-818)

A posição de Ferrajoli é oposta àquela de Losano, jusfilósofo positivista aberto ao aspecto social do direito, por meio da contribuição de Jhering e da concepção culturalista. ${ }^{14}$ Losano dedicou-se à análise da cultura jurídica e também ao estudos de sistemas jurídicos, além da informática jurídica. ${ }^{15} \mathrm{~A}$ abordagem teórica, via cultura jurídica, permite ao autor piemontes uma contextualização ampla do trabalho de Bobbio, com a diferenciação de forma bastante acurada de suas várias fases de pesquisa, considerando o contexto vivido e entendendo-o, particularmente após 1973, com uma postura pós-positivista.

O entendimento de Losano baseia-se no afastamento de Bobbio de alguns elementos do positivismo normativo kelseniano, por meio da abertura ao funcionalismo jurídico e à sociologia do direito. A abordagem sobre o objetivo e a função do direito, temas evitados por Kelsen, denotam na teoria de Bobbio a preocupação com a 'evolução' do Estado e uma teoria do direito que queira manter-se atualizada com os tempos. (LOSANO, 2007, p. XLII e XLVIII) A abertura de Bobbio à sociologia e ao funcionalismo jurídico não implica, porém, em negar a importância e a contribuição da teoria de Kelsen, mas em realizar um avanço em relação àquela. (BOBBIO, 2007, p. 210)

A concepção que Losano apresenta do pós-positivismo denota-se particularmente próxima aquela de Bobbio e não focada apenas na proposta de Dworkin, mas considerando o pós-positivismo como fruto de uma dinâmica do próprio positivismo jurídico, como resposta às mudanças políticas e sociais, revendo as atribuições do Estado legislador e do juiz executor. Na exposição de Losano, o termo "pós" não é entendido como ruptura para com o positivismo jurídico, mas como um movimento de contribuição e adequação da doutrina positivista, e

\footnotetext{
${ }^{14}$ Entrevista à Mario G. Losano, In Revista da Faculdade de Direito - UFPR, Curitiba, vol. 59, n. 2, 2014, p 207: "Não há uma teoria que explique tudo no Direito. Existem abordagens. Eu continuo trabalhando com Kelsen e Jhering. São as duas faces do Direito. Exatamente de Jhering me fascina esta abertura à sociedade, sobretudo na última parte da sua vida, que foi a parte mais criticada por seus contemporâneos na Alemanha6. Posso dizer que uso a metodologia que creio mais apta para o tipo de investigação que faço. Se preciso fazer uma pesquisa sobre o direito positivo, sou rigorosamente positivista kelseniano. Mas, se é uma pesquisa sobre o Movimento Sem Terra, com Kelsen não chego a uma conclusão aceitável."

${ }^{15}$ Mario Losano também é um brasilianista, com obras dedicadas à Tobias Barreto e a influência italiana sobre aquele brasileiro. Das obras de Losano sobre teoria e cultura jurídica, indico especificamente "Sistema e estrutura no direito" (composto de 3 volumes). Sobre sistemas jurídicos "Os grandes sistemas jurídicos”. Tradução de Ana Falcão Bastos e Luís Leitão, Editorial Presença (Portugal) - Livraria Martins Fontes (Brasil), Lisboa 1979.
} 
dentro da qual se encaixa a contribuição estrutural e funcionalista do direito de Bobbio, após o positivismo normativo de Kelsen. ${ }^{16}$

\section{CONCLUSÃO}

A obra de Bobbio é contextualizada em diferentes fases e interesses de pesquisa, que partem de problemas específicos de filosofia e de teoria geral do direito, passam pelo estudo crítico até a flexibilização de elementos do positivismo jurídico e a propositura de uma teoria funcional do direito.

O desenvolvimento da pesquisa de Bobbio pode ser contextualizado em uma crise moral e social, que abarca também a ciência jurídica e as ciências em geral, após a primeira e a segunda-guerra mundial, fruto da consciência das falácias de sistemas ditatoriais e das atrocidades cometidas em nome de objetivos políticos. Diante da crise, observa-se um certo renascimento do jusnaturalismo, enquanto Bobbio aproxima-se, muitas vezes de forma crítica, do positivismo normativo de Hans Kelsen. A contraposição entre as duas concepções do direito não afasta Bobbio da reflexão sobre a função e o objetivo do direito, enquanto fruto de escolhas políticas e ao mesmo tempo parte do social.

Nesse sentido, delineou-se a nova fase de pesquisa de Bobbio, na qual não apenas manifestou contínuo interesse pelo estudo do poder, mas defendeu que é por meio desse que a teoria jurídica e a teoria política se complementam. A pesquisa jurídica de Bobbio, passa a relacionar-se então com uma concepção de política voltada aos valores sociais contextualizados em uma liberal-democracia e refutando as pretensões de uma ciência jurídica isolada das ideologias sociais.

Bobbio evidencia que por meio das transformações aportadas ao Estado (tornando-o Estado Social) houve transformações na concepção e na função social do direito. A "nova" concepção evidenciada pelo autor torinês aproxima-se da concepção de direito de Santi Romano, ao denotar o direito como ordenamento com função de organização ou direção social, conjugando-a à concepção de Kelsen que entende o direito como forma de controle social. Nessa concepção, o direito não é isolado, mas sim contextualizado socialmente evidenciando que a sociologia do direito ganha particular espaço na tarefa de auxiliar a teoria geral do direito. Observa-se, portanto, que a concepção e a evidência das normas premiais por Bobbio permitem flexibilizar elementos do positivismo kelseniano como a concepção eminentemente coercitiva do ordenamento jurídico e do direito, tornando-os permeados por concepções sociais em seus valores e na análise e compreensão do direito não apenas como estrutura, mas como função de direção social.

Neste contexto, Bobbio evidencia que entre positivismo e pós-positivismo tem-se mudanças, mas que

${ }^{16}$ LOSANO, 2007, p. XLII. Losano não se manifesta com frequência sobre o debate pós-positivista, consta referência do autor no citado prefácio, mas na obra 'Sistema e estrutura no direito', ele tem uma abordagem histórico-analítica na qual aborda com fortes críticas o termo 'pós-modernidade', mas esquiva-se do debate sobre a concepção do termo 'pós-positivismo'. 
essas mudanças não são tão profundas ao ponto de delinear uma ruptura, mas apenas uma complementariedade, fruto dos novos tempos. Nesse sentido, ao reconhecer a validade das críticas ao positivismo jurídico (no que tange à coerência e completude do ordenamento jurídico e interpretação lógica do direito) o autor torinês, desde a sua fase de maior pesquisa ao positivismo optava por manter-se longe de um positivismo em sentido estrito e optava pelo sentido amplo (reconhecendo dentre outros motivos a forte importância da interpretação). A concepção de continuidade e descontinuidade entre positivismo e pós-positivismo de Bobbio é bem evidenciada, por meio da influência de Tullio Ascarelli e Genaro Carriò, e muito próxima da posterior concepção de Mario Losano, muito embora contraditada por Luigi Ferrajoli.

Bobbio pode então ser entendido como pós-positivista, a partir da flexibilização de elementos do juspositivismo e considerando o mais recente movimento como uma dinâmica de desenvolvimento que amplia os critérios de aplicação do direito, abarcando uma concepção funcional e permeável dos ideais de liberdade e justiça.

\title{
BETWEEN POSITIVISM AND POST-POSITIVISM: FLEXIBILIZATION OF ELEMENTS ON NORBERTO BOBBIO'S WRITINGS
}

\begin{abstract}
The contribution of Norberto Bobbio to the general theory of law is composed of several phases that go from research on themes related to custom and analogy, to the critical interest to the legal positivism of Kelsen and finally approaching the functional character of law. The research interest to the Italian author enrich his trajectory and outline the flexibilization of legal positivism elements, allowing the extension of the right to field sociology, politics and philosophy of law. In this article, the question is whether the flexibilization of some aspects of positivist doctrine allow us to understand the conception of Bobbio of law as post-positivist. In this context, besides the writings of Bobbio, confronted the opinions of Luigi Ferrajoli that defines how paleo-positivist, and Mario Losano that analyzing the plurality of Bobbio research phases, considers its final phase, starting from the 70s such as postpositivist. As a result, was obtained that Bobbio can be understood in certain ways, as post-positivist, considering the flexibilization of legal positivism elements and the dynamic expansion of criteria of the law application, covering in a functional conception and permeable ideals of freedom and justice.
\end{abstract}

Keywords: Norberto Bobbio; Juspositivism; Pos-Positivism; Sociology; Function of Law.

\section{REFERENCIAS}

ANTONI, Carlo. La restaurazione del diritto di natura. Venezia: Neri Pozza, 1959, 259 p.

ASCARELLI, Tullio. Panorama do Direito Comercial. 2. ed. Sorocaba: Editora Minelli, 2007, 154 p. 
BOBBIO, Norberto. L'indirizzo fenomenologico nella filosofia sociale e giuridica. Torino: Istituto giuridico della R. Università, 1934, $157 \mathrm{p}$.

L'analogia nella logica del diritto. Torino: Istituto giuridico della R. Università, 1938, 216 p.

"Tullio Ascarelli". In "Belfagor", XIX, 1964, p. 412-424, 547-565.

CXL p.

Teoria e ideologia nella dottrina di Santi Romano. In: RUFFIA, Paolo Biscaretti di (org.). Le dottrine giuridiche di oggi el'insegnamento di Santi Romano. Milano: Giuffrè, 1977, p. 25-43.

Teoria generale del diritto. Torino: Giappichelli, 1993, 297 p.

Giusnaturalismo e giuspositivismo. In: Enciclopedia delle scienze sociali. Roma: Treccani, 1994.

Disponível em: http://www.treccani.it/enciclopedia/giusnaturalismo-e-giuspositivismo_\%28Enciclopediadelle-scienze-sociali\%29/, acessado em 09 nov. 2015.

O positivismo jurídico. Lições de filosofia do direito. São Paulo: Ícone, 1995, 239 p.

Teoria do Ordenamento Jurídico. Brasília: Editora UnB, 1997, 184 p.

Diário de um século: Autobiografia. Rio de Janeiro: Campus, 1998, 261 p.

Teoria da norma jurídica. Bauru: EDIPRO, 2001, 192 p.

A era dos direitos. Rio de Janeiro: Elsevier, 2004, 212 p.

Prologo, in FERRAJOLI, Luigi. Direito e Razão. Teoria do garantismo jurídico. $7^{\circ}$ ed. Madrid: Editora Trotta, 2005, p. 13-19.

Da estrutura à função. Novos estudos de teoria do Direito. Barueri. São Paulo: Manole, 2007, 285 p.

Da estrutura à função. Novos estudos de teoria do Direito. Barueri. São Paulo: Manole, 2007, prefácio à edição brasileira, p. XIX-XLIX.

Dizionario di filosofia politica (treccani). Disponível em http://www.treccani.it/enciclopedia/norbertobobbio_\%28Dizionario-di-filosofia\%29/, acessado em 18 Agost. 2015.

CARRIó, Genaro R. Sul concetto di obbligo giuridico, in “Rivista di filosofia”, LVII, 1966, p. 141-155.

DWORKIN, Ronald. Taking rights seriously. London: Duckworth, 1977, 293 p.

FARALLI, Carla. La filosofia del diritto nel secondo Novecento. Il Contributo italiano alla storia del Pensiero Diritto (2012). Disponível em http://www.treccani.it/enciclopedia/la-filosofia-del-diritto-nel-secondonovecento_\%28Il-Contributo-italiano-alla-storia-del-Pensiero:-Diritto\%29/, acessado em 22 out. 2015.

FERRAJOLI, Luigi. Derecho y Razon. $7^{\circ}$ ed. Madrid: Editora Trotta, 2005, 1019 p.

El constitucionalismo entre principios y reglas. In DOXA, n. 35, 2012, p. 791-817.

FERRAJOLI, Luigi; STRECK, Lênio; TRINDADE, André K. (orgs.). Garantismo, hermenêutica e (neo) constitucionalismo: um debate com Luigi Ferrajoli, Alexandre Morais da Rosa [et al.]. Porto Alegre: Livraria do Advogado, 2012, $260 \mathrm{p}$.

GUIBENTIF, Pierre. O direito na obra de Niklas Luhmann. Etapas de uma evolução teórica. In: SANTOS, José Manuel (org.). O Pensamento de Niklas Luhmann. Universidade da Beira Interior, 2005. Disponível em cadeiras.iscte.pt/SDir/2006_Dir_na_obra_de_niklas_Luhmann.pdf, acessado em 28 set. 2015.

HART, Herbert L. A. O conceito de direito. São Paulo: WMF Martins Fontes, 2012, 399 p.

HAYEK, Friedrich August von. The principles of a liberal social order. In "Il Politico", XXXI, 1966, p. 601-617.

IHERING, Rudolf von. A finalidade do direito. 1. ed. Campinas: Bookseller, 2002, $2 \mathrm{v}$. 
KELSEN, Hans. Teoria Geral do Direito e do Estado. São Paulo: Martins Fontes, 1998, 637 p. Teoria pura do direito. 6 ed. São Paulo: Martins Fontes, 2003, 427 p.

LOSANO, Mario G. O pensamento de Norberto Bobbio, do positivismo jurídico à função do direito. In:

Sistema e Estrutura no direito: o século XX. São Paulo: WMF Martins Fontes, 201 1, 3 v.

Os grandes sistemas jurídicos. São Paulo: Martins Fontes, 2007, 676 p.

OLIVEIRA JÚNIOR, José Alceu de. Prefácio, In PASOLD, Cesar Luiz. Ensaio sobre a ética de Norberto Bobbio. Florianópolis: Conceito Editorial, 2008,312 p.

RADBRUCH, Gustav. Gesetzliches Unrecht und übergesetzliches Recht, in Süddeutsche Juristenzeitung, v. 1, p. 105-108, 1946.

Propedeutica alla filosofia del diritto. Torino: Giapichelli, 1959, 237 p.

REALE, Miguel. Legados de Norberto Bobbio. Disponível no site www.academia.org.br/abl/media/prosa13.pdf, acessado em 22 Agost. 2015.

A Teoria da Interpretação Segundo Tullio Ascarelli, in Revista da Faculdade de Direito da Universidade de São Paulo, v. 74 (1979) p. 197. Disponível em http://www.revistas.usp.br/rfdusp/article/view/66878/69488, acesso em 25 set. 2015 .

ROMANO, Santi. O ordenamento jurídico. Florianópolis: Boiteux, 2008, 252 p.

SOUZA, María de Lourdes (1998). «Del uso alternativo del derecho al garantismo: una evolución paradójica». Anuario de Filosofía del Derecho (15). Disponível em: www.dialnet.unirioja.es/descarga/articulo/142382.pdf Acessado em 11 Nov. 2015.

Trabalho enviado em 10 de dezembro de 2015.

Aceito em 13 de novembro de 2016. 